UDC 340.13

LBC 67.0

\title{
THE CERTAINTY OF LAW AND TECHNICAL LEGAL MEANS OF ITS ENSURING ${ }^{1}$
}

\author{
Marina L. Davydova \\ Volgograd State University, Volgograd, Russian Federation
}

\begin{abstract}
Introduction: the uncertainty is not always the lack of the legal regulation. There are situations when, on the contrary, the excessive certainty is harmful. However, to achieve the uncertainty of law is much easier than to ensure its certainty. Therefore, the discussion of technical legal means in the scientific literature is conducted primarily in the context of raising or ensuring the certainty of law. The author classifies these technical legal means. Using the formal and legal method, the author analyzes the legal instruments that reduce the level of law uncertainty. As a result, it is proposed to divide these instruments depending on what is understood by law uncertainty (the uncertainty of a regulated situation or the regulation itself: the normative or individual one). Most technical legal means (estimative concepts, principles, and the combinations of dispositive and peremptory norms, of absolutely and relatively certain elements, conflict norms, the possibility of applying analogy of law, exceptions) are used to maintain the optimal balance of certainty and uncertainty. Some means (legal definitions and legal structures) are naturally designed to eliminate uncertainty. To perform this function the legal definitions and structures must be inextricably linked with each other.
\end{abstract}

Key words: certainty of law, uncertainty of law, legal means, legal presumptions, legal fictions, estimative concepts, legal definitions, legal structures

УДК 340.13

ББК 67.0

\section{ОПРЕДЕЛЕННОСТЬ ПРАВА И ТЕХНИКО-ЮРИДИЧЕСКИЕ СРЕДСТВА ЕЕ ОБЕСПЕЧЕНИЯ ${ }^{1}$}

\author{
Марина Леонидовна Давыдова \\ Волгоградский государственный университет, г. Волгоград, Российская Федерация
}

\begin{abstract}
Введение. Неопределенность не всегда является недостатком правового регулирования. Существуют ситуации, при которых, наоборот, избыточная определенность вредна. Однако добиться неопределенности права гораздо легче, чем обеспечить его определенность. Поэтому обсуждение технико-юридических средств в научной литературе ведется преимущественно в контексте повышения или обеспечения определенности права. Автор ставит цель классифицировать данные технико-юридические средства. С применением формально-юридического метода в статье проводится анализ юридического инструментария, снижающего уровень неопределенности права. В результате предлагается разделить все средства в зависимости от того, что понимается под правовой неопределенностью (неопределенность регулируемой ситуации или самого правового регулирования: нормативного или индивидуального). В статье обосновывается вывод о том, что б большинство технико-юридических средств (оценочные понятия, принципы, сочетание диспозитивных и 훌 императивных норм, абсолютно и относительно определенных элементов, коллизионные предписания, возможность применения права по аналогии, исключения) используются для поддержания оптимального баланса определенности и неопределенности, и лишь некоторые из них (правовые дефиниции и юридические конструкции) по природе своей призваны устранять неопределенность. Выполнить данную функцию дефиниции и конструкции могут лишь находясь в неразрывной связи друг с другом.

Ключевые слова: определенность права, неопределенность права, средства юридической техники, правовые презумпции, правовые фикции, оценочные понятия, правовые дефиниции, юридические конструкции.
\end{abstract}




\section{Введение}

Проблема правовой определенности и неопределенности в последние годы привлекает значительное внимание в рамках теоретико-правовых [3; 4] и отраслевых [7; 8] научных исследований. Далеко не всегда при этом неопределенность рассматривается как однозначный недостаток правового регулирования. Наоборот, в ряде ситуаций избыточная определенность оказывается не меньшим злом (с этим связано, например, существование такого феномена, как «квалифицированное молчание законодателя» [2]). Однако в порядке постановки научной проблемы говорить о «достижении неопределенности права» не имело бы смысла, так как достичь неопределенности чего-либо значительно проще, чем ее преодолеть (как правило, достаточно просто ничего не делать, и энтропия сама обеспечит нужный результат). Именно поэтому в качестве научной проблемы принято рассматривать движение от неопределенности права к его определенности. Это движение требует использования целого ряда технико-юридических средств, классификации которых и посвящена настоящая статья.

\section{Варианты классификации технико-юридических средств}

Далеко не все авторы стремятся выстроить все средства в четкую систему, часто ограничиваясь открытым перечнем. Так, Н.А. Власенко в качестве средств, обеспечивающих ту или иную степень определенности правового регулирования, называет принципы права, рамочные законы, конкретизацию, юридические конструкции, презумпции, фикции, оценочные понятия, судебное усмотрение, правовой обычай [4, с. 73-110]. Одну из возможных классификаций техникоюридических средств предлагает А.В. Демин, который делит их на три группы: средства, обеспечивающие определенность права (правовые презумпции и фикции); средства, преодолевающие неопределенность (аналогия); относительно-определенные средства (оценочные понятия, диспозитивные и бланкетные правовые нормы) [7, с. 32-34].
По нашему мнению, классификация средств должна ставиться в зависимость от того, какого рода неопределенность они призваны устранить или компенсировать. Действительно, для того, чтобы систематизировать технико-юридические средства, направленные на снятие неопределенности в праве, необходимо уточнить, всегда ли мы понимаем одно и то же под самой неопределенностью. Как представляется, последняя может предстать в двух своих аспектах:

- неопределенность регулируемой ситуации;

- неопределенность самого правового регулирования.

В первом случае неопределенность касается жизненных отношений, подвергающихся регулированию. Другими словами, нам ясно, чего хочет законодатель, но недостаточно информации о том, подходит ли конкретная ситуация под правовую норму (отсутствует факт или нет необходимой информации о фактах). Для таких неопределенных ситуаций существуют вполне определенные правила правовые презумпции и фикции, которые не столько повышают определенность права, сколько преодолевают неопределенность жизни.

К примеру, у нас не возникает сомнений по поводу того, что виновный должен возместить ущерб, но нет уверенности, что в конкретной ситуации именно перевозчик виновен в повреждении груза. Учитывая, что подобные сомнения вполне типичны и предсказуемы, законодатель устанавливает презумпцию ответственности перевозчика, возлагающую на него бремя доказывания и компенсирующую тем самым неопределенность реальных обстоятельств.

Неопределенность правового регулирования, в свою очередь, можно разделить на две разновидности:

- неопределенность нормативно-правового регулирования;

- неопределенность индивидуально-правового регулирования.

Вторая касается прежде всего судебных решений. Именно в связи с ними чаще всего обсуждается принцип правовой определенности, который складывается из соблюдения процессуальных гарантий, обеспечивающих 
законность, стабильность, ожидаемость правоприменительного акта. На определенность судебного решения влияют количество возможных пересмотров, единообразие правоприменительной практики и другие факторы, которые нельзя свести лишь к юридической технике. Так, И.С. Дикарев в качестве элементов принципа правовой определенности называет: (1) стабильность правового регулирования; (2) осведомленность гражданина относительно действующих законов и подзаконных нормативных актов, а также правоприменительных актов, затрагивающих его права и законные интересы; (3) ясность, недвусмысленность и согласованность правовых норм, правоприменительных решений; (4) единообразное применение закона (в том числе единство судебной практики); (5) стабильность правоприменительных решений; (6) исполнимость судебных решений [8, с. 12-13].

Неопределенность нормативно-правового регулирования предполагает отсутствие четко выраженной воли законодателя. Она требует использования технико-юридических средств, которые не столько устраняют неопределенность, сколько дозируют ее, обеспечивают некий баланс определенности и неопределенности в нормативном тексте. К ним относятся оценочные понятия, принципы, сочетание диспозитивных и императивных норм, абсолютно и относительно определенных элементов, коллизионные предписания, возможность применения права по аналогии, исключения.

Если сравнить эти средства с теми, которые направлены на преодоление неопределенности регулируемых отношений, можно увидеть, что причина их существования не столько в неопределенности, сколько в непредсказуемости, многовариантности этих отношений. В случае с презумпциями и фикциями законодатель точно знает, чего хочет, но понимает, что в жизни может недоставать фактов для реализации его воли. А средства, связанные с неопределенностью самого правового регулирования, исходят из того, что невозможно предусмотреть все варианты развития отношений, и, следовательно, нет смысла придумывать точные правила для каждого из них. Законодатель в этом случае часть вопросов решает в императивном порядке, а часть - отдает на усмот- рение сторон («...если иное не предусмотрено договором») или правоприменителя (оценочные понятия, аналогия). Для этих средств не существует универсального количественного критерия, который определял бы оптимальный объем их использования. Для каждой ситуации этот вопрос решается индивидуально с учетом установленных императивов. Мастерство законодателя здесь проявляется как раз в том, чтобы подобрать оптимальное сочетание императивных и диспозитивных регуляторов поддержать баланс определенности и неопределенности.

В арсенале технико-юридических средств есть, однако, и такие, которые по природе своей призваны обеспечивать определенность правового регулирования. Это дефиниции и юридические конструкции. В отношении этих средств, в отличие от предыдущей группы, неправильно говорить о недостаточном или избыточном их количестве в тексте закона. Решающим критерием для дефиниций и конструкций является достаточная их проработанность, качество, способное обеспечить определенность.

\section{Правовые дефиниции и юридические конструкции: требования и соотношение}

Сказанное, естественно, не означает, что в отношении дефиниций, например, работает принцип «чем больше, тем лучше». Однако случаев, когда использование нормативной дефиниции однозначно выглядит излишним, по нашему мнению не так много. Теоретически можно выделить три таких ситуации:

1) отсутствие неопределенности или мнимая неопределенность. Здесь имеет место понятный термин, дефиниция которого не добавляет новой информации, раскрывающей его значение;

2) дублирование дефиниций. Как замечает В.Ю. Туранин, «использование разных определений одного и того же термина в нескольких законодательных актах все-таки возможно, но только в том случае, если каждая последующая дефиниция уточняет признаки соответствующего понятия (термина) и не противоречит уже имеющемуся определению» $[10$, c. 226$]$; 
3) отсутствие в дефиниции юридических признаков понятия. Если в первых двух ситуациях наличие определения еще можно объяснить тем, что, создавая некоторую избыточность правовой информации, законодатель стремится сделать акцент на наиболее значимых аспектах правового регулирования, установить дополнительные гарантии против неправильного толкования тех или иных терминов (аргумент, впрочем, сомнительный, учитывая, что малейшие разночтения в дублирующих друг друга дефинициях неизбежно порождают сложности при их толковании и практическом применении), то последний случай вряд ли может быть чем-то оправдан.

Приведем пример. Статья 5 Лесного кодекса РФ называется «Понятие леса» и звучит следующим образом: «Использование, охрана, защита, воспроизводство лесов осуществляются исходя из понятия о лесе как об экологической системе или как о природном ресурсе». В данном случае дефиниция, то есть определение понятия, вообще отсутствует, а вместо нее упоминаются два значения, в которых может использоваться соответствующее понятие. При этом они, во-первых, представлены в альтернативной форме, а во-вторых, ни один из вариантов не содержит юридической характеристики понятия, которая позволила бы практически применить его. По сути, речь идет о правовой декларации, замаскированной под дефиницию понятия. Действительно, в преамбуле кодекса информация о том, что лес является экологической системой и важным природным ресурсом, выглядела бы значительно уместнее.

Обращаясь к юридическим конструкциям, следует заметить, что их роль в обеспечении определенности права существенно зависит от того, как понимается природа самой юридической конструкции. На этот счет в литературе существует две точки зрения: правотворческая и теоретическая (подробнее см.: $[6$, c. $4-16])$.

Правотворческий подход предполагает, что юридическая конструкция создается законодателем в процессе построения текста нормативного акта. Крайний вариант такой позиции можем встретить в учебнике под редакцией Ю.Г. Арзамасова, где конструкции определяются как «схемы-шаблоны, определенные образцы проектов нормативных доку- ментов, которыми пользуются компетентные органы и должностные лица при подготовке юридических документов» [9, с. 110].

Недостатки этого подхода заключаются в том, что, с одной стороны, под понятие юридической конструкции в такой ее трактовке подходит все, что угодно: от отдельного предложения до целого нормативного акта. С другой стороны, говорить об общих признаках или функциях конструкций при таком подходе достаточно сложно, поэтому особой пользы, с точки зрения научного исследования конструкций, он не имеет.

Теоретический подход под юридической конструкцией понимает внутреннюю структуру правовых понятий, средство юридического мышления, выявления юридически значимых элементов понятия (из законодательства, доктрины, практики). Именно в такой трактовке конструкция обеспечивает содержательную определенность права.

С точки зрения второго подхода, юридическая конструкция оказывается тесно связана с дефиницией, так как дефиниция - это не единственный, но один из удобных способов выражения элементов конструкции. Для рассматриваемых понятий характерны следующие варианты соотношения:

1. Полное несовпадение, когда дефиниция не содержит юридических признаков понятия, как в приведенном выше примере из Лесного кодекса.

2. Дефиниция отражает лишь некоторые признаки понятия, образующие юридическую конструкцию. Так, определение принудительного труда в ст. 4 Трудового кодекса РФ содержит главный его признак: выполнение работы под угрозой применения какого-либо наказания. За рамками дефиниции в этой статье перечисляются также наличие у работника по закону права отказаться от работы и исключения, не являющиеся принудительным трудом. В итоге исчерпывающим образом конструкция принудительного труда может быть представлена только на основании анализа всей статьи. Соответственно, по объему эта конструкция шире, чем нормативная дефиниция.

3. Конструкция и дефиниция совпадают друг с другом в тех случаях, когда формулировка дефиниции настолько выверена, что все 
элементы юридической конструкции нашли в ней свое отражение. Примерами подобных дефиниций являются классические дефиниции гражданского права. «Сделками признаются действия граждан и юридических лиц, направленные на установление, изменение или прекращение гражданских прав и обязанностей» (ст. 153 ГК РФ); «По договору подряда одна сторона (подрядчик) обязуется выполнить по заданию другой стороны (заказчика) определенную работу и сдать ее результат заказчику, а заказчик обязуется принять результат работы и оплатить его» (ст. 702 ГК РФ); «...в порядке универсального правопреемства, то есть в неизменном виде как единое целое и в один и тот же момент» (ст. 1110 ГК РФ). Неслучайно С.С. Алексеев подчеркивает, что наиболее разработаны юридические конструкции в кодифицированных актах [1, с. 489], ведь, как правило, кодификация выступает следствием существования устоявшейся правовой доктрины, отражает многолетний опыт совершенствования юридических формул.

\section{Выводы}

Таким образом, юридическая конструкция и правовая дефиниции - это средства, играющие основную роль в обеспечении определенности права. Юридическая конструкция при этом выступает как критерий качества правовой дефиниции. Конечно, два этих средства юридической техники не совпадают друг с другом. Но в идеале конструкция должна быть настолько проработана, чтобы ее можно было «свернуть» в четкую дефиницию. Такую дефиницию в итоге можно определить как «сгусток правовой теории» [5, с. 217], который в концентрированном виде представляет информацию о правовом понятии. Количество элементов юридической конструкции, отраженных в дефиниции, должно быть минимально необходимым и достаточным, чтобы дефиниция не была перегружена лишней информацией, а конструкция в полной мере соответствовала закону юридической красоты.

\section{ПРИМЕЧАНИЕ}

1 Исследование выполнено при финансовой поддержке РФФИ и Администрации Волгоградской области в рамках научного проекта № 16-13-34025 по теме «Технология электронного правительства в системе государственных и муниципальных услуг Волгоградской области: социально-правовое обеспечение эффективной реализации».

\section{СПИСОК ЛИТЕРАТУРЫ}

1. Алексеев, С. С. Общая теория права / С. С. Алексеев. - 2-е изд., перераб. и доп. - М. : Велби : Проспект, 2008. - 576 с.

2. Баранов, В. М. «Квалифицированное молчание законодателя» как общеправовой феномен: к вопросу о сущности и сфере функционирования пробелов в праве / В. М. Баранов // Пробелы в российском законодательстве. - 2008. - № 1. - С. 75-78.

3. Власенко, Н. А. Проблемы правовой неопределенности / Н. А. Власенко. - М. : Ин-т законодательства и сравнительного правоведения при Правительстве Рос. Федерации : ИНФРА-М, 2015. - 176 с.

4. Власенко, Н. А. Разумность и определенность в правовом регулировании / Н. А. Власенко. - М. : Инфра-М, 2015. - 157 с.

5. Вопленко, Н. Н. Очерки общей теории права / Н. Н. Вопленко. - Волгоград : Изд-во ВолГУ, 2009. - $897 \mathrm{c}$.

6. Давыдова, М. Л. Юридическая конструкция как средство формирования профессионального мышления студента-юриста / М. Л. Давыдова // Право и образование. - 2013. - № 4. - С. 4-16.

7. Демин, А. В. Неопределенность в налоговом праве и правовые средства ее преодоления / А. В. Демин. - М. : Инфра-М : РИОР, 2013. - 246 с.

8. Дикарев, И. С. Принцип правовой определенности и законная сила судебного решения в уголовном процессе / И. С. Дикарев. - Волгоград : Изд-во ВолГУ, 2015.- $175 \mathrm{c}$.

9. Нормография: теория и технология нормотворчества / под ред. Ю. Г. Арзамасова. - М. : Юрайт, 2017. -460 c.

10. Туранин, В. Ю. Юридическая терминология в современном российском законодательстве (теоретико-правовое исследование) : дис. ... д-ра юрид. наук / Туранин Владислав Юрьевич. - Белгород, 2017. $-437 \mathrm{c}$.

\section{REFERENCES}

1. Alekseev S.S. Obshchaya teoriya prava [General Theory of Law]. Moscow, TK "Velbi" Publ.; Prospekt Publ., 2008. 576 p.

2. Baranov V.M. «Kvalifitsirovannoe molchanie zakonodatelya» kak obshchepravovoy 
fenomen: $k$ voprosu o sushchnosti i sfere funktsionirovaniya probelov v prave ["The Qualified Silence of the Legislator" as a General Legal Phenomenon: to the Nature and Scope of Gaps in the Law]. Probely $v$ rossiyskom zakonodatelstve, 2008, no. 1, pp. 75-78.

3. Vlasenko N.A. Problemy pravovoy neopredelennosti [Problems of Legal Uncertainty]. Moscow, In-t zakonodatelstva i sravnitelnogo pravovedeniya pri Pravitelstve Ros. Federatsii; INFRA-M Publ., 2015. 176p.

4. Vlasenko N.A. Razumnost $i$ opredelennost $v$ pravovom regulirovanii [Reason and Certainty in Legal Regulation]. Moscow, Infra-M Publ.; IZiSP Publ., 2015. 157 p.

5. Voplenko N.N. Ocherki obshchey teorii prava [Essays on the General Theory of Law]. Volgograd, Izd-vo VolGU, 2009. 898 p.

6. Davydova M.L. Yuridicheskaya konstruktsiya kak sredstvo formirovaniya professionalnogo myshleniya studenta-yurista [Legal Construction as a
Means of Forming the Professional Thinking of a Law Student]. Pravo i obrazovanie, 2013, no. 4, pp. 4-16.

7. Demin A.V. Neopredelennost $v$ nalogovom prave $i$ pravovye sredstva ee preodoleniya [Uncertainty in Tax Law and Legal Means to Overcome It]. Moscow, Infra-M Publ.; RIOR Publ., 2013. 246 p.

8. Dikarev I.S. Printsip pravovoy opredelennosti $i$ zakonnaya sila sudebnogo resheniya $v$ ugolovnom protsesse [The Principle of Legal Certainty and the Legal Force of a Judicial Decision in Criminal Proceedings]. Volgograd, Izd-vo VolGU, 2015. 175 p.

9. Arzamasov Yu.G., ed. Normografiya: teoriya $i$ tekhnologiya normotvorchestva [Normography: Theory and Technology of Rulemaking]. Moscow, Yurayt Publ., 2017. 460 p.

10. Turanin V.Yu. Yuridicheskaya terminologiya $v$ sovremennom rossiyskom zakonodatelstve (teoretikopravovoe issledovanie): dis. ... d-ra yurid. nauk [Legal Terminology in Modern Russian Legislation: Theoretical and Legal Research. Dr. jurid. sci. diss.]. Belgorod, 2017. $437 \mathrm{p}$.

\section{Information about the Author}

Marina L. Davydova, Doctor of Juridical Sciences, Professor, Head of the Department of Constitutional and Municipal Law, Volgograd State University, Prosp. Universitetsky, 100, 400062 Volgograd, Russian Federation, davidovavlg@gmail.com.

\section{Информация об авторе}

Давыдова Марина Леонидовна, доктор юридических наук, профессор, заведующая кафедрой конституционного и муниципального права, Волгоградский государственный университет, просп. Университетский, 100, 420067 г. Волгоград, Российская Федерация, davidovavlg@gmail.com. 